\title{
Monitoring the setting process of alkali-activated slag-fly ash cements with ultrasonic P-wave velocity
}

\author{
Siva Uppalapati*, Lucie Vandewalle, Özlem Cizer \\ KU Leuven, Department of Civil Engineering, Materials and Constructions Division, Kasteelpark Arenberg 40 (2448), 3001 Leuven, Belgium
}

\section{H I G H L I G H T S}

- Setting behavior of AASF cements is studied by using UPV measurements.

- Early-age reaction process of AASF is monitored by using ultrasonic measurements.

- Specific ranges of UPV are suggested to estimate the setting time in AASF cements.

\section{A R T I C L E I N F O}

\section{Article history:}

Received 28 May 2020

Received in revised form 18 September 2020

Accepted 1 November 2020

Available online $\mathrm{xxxx}$

\section{Keywords:}

Setting time

Ultrasonic P-wave velocity

Alkali-activated slag/fly ash cements

Reaction degree

\begin{abstract}
A B S T R A C T
One of the shortcomings of alkali-activated materials in concrete applications is quick setting time that has been poorly understood. The objective of this study is to explore the setting process of sodium silicate-activated slag-fly ash cements using ultrasonic P-wave velocity. The effect of incorporating sodium carbonate and sodium sulfate on the setting process of sodium silicate-activated samples is also investigated. The results show that partial substitution of sodium silicate with sodium carbonate and sodium sulfate activators has no noticeable effect on the initial setting time, while the final setting time increases significantly. Comparative assessment of ultrasonic measurements with Vicat setting times and calorimetry heat flow curves shows that condensation reaction between the aluminosilicate units formed near the particle surface is most likely responsible for setting. A specific ultrasonic velocity range can be used to estimate the setting times of the studied AASF cements.
\end{abstract}

(c) 2020 Elsevier Ltd. All rights reserved.

\section{Introduction}

Alkali-activated materials developed from blast-furnace slag and fly ash can offer a low-carbon alternative to Portland cement with their advantages of high strength development at early-ages $[1,2]$, and excellent resistance against fire and chemical attacks $[3,4]$. However, they also have critical shortcomings such as quick setting process, poor workability and large shrinkage deformations which cannot secure their performant functions in concrete applications [2,5-9].

Similar to hydrating Portland cements, alkali-activated materials are transformed progressively from a liquid precursor to a solid gel as a result of complex chemical reactions composed of dissolution, gelation, polycondensation and densification [10]. The rate of these reactions determines the setting time that is significantly controlled by the solid precursor, activator and curing temperature. Co-activation of calcium-rich slag and aluminosilicate-rich fly ash has been shown to control the setting process and

\footnotetext{
* Corresponding author.
}

counterbalance the tendency of quick setting in alkali-activated slag and retards setting [11]. The primary reaction product of alkali-activated slag is C-S-H with Al in its composition [12], whereas the alkali activation of fly ash results in the formation of three-dimensional aluminosilicate networks (N-A-S-H) via polycondensation [13]. Coexistence and synergy between the C-A-S-H and aluminosilicate gels (N-A-S-H) with higher degree of cross links [14-18] in alkali-activation of slag-fly ash blends (AASF) offer advantages not only for setting but also for workability, microstructure, durability and mechanical properties. Recent studies have reported that the setting time of fly ash-based and metakaolin-based geopolymers is accelerated with the addition of calcium-rich sources such as blast furnace slag because both the rate and extend of fly ash and metakaolin dissolution are enhanced resulting in an increased volume of gel formation [1924].

Previous studies have reported that type and concentration of the activator are the most dominant parameters that influence the setting process of alkali-activated slag [25-27] High activator concentration is often necessary to achieve desired strength, but 
this can lead to prohibitively short setting times (as short as $30 \mathrm{~min}$ ) due to the acceleration effect of highly alkaline activator [26,28-30]. Some researchers have shown that the nature of anions in the activator significantly affects the setting time of alkaliactivated slag, as the anions in the solution can react directly with the ions dissolved from the source materials and forms stable reaction products $[25,31,32]$.

A mix of sodium silicate and sodium hydroxide is the most widely used activator in alkali-activated slag cements that show comparable strength properties to Portland cement [33]. However, these cements set rather quickly due to presence of soluble $\mathrm{SiO}_{4}^{4-}$, which renders them unsuitable for concrete applications [34,35] Also, the production process of sodium silicate solution is expensive with high environmental impact [36] Therefore, the use of naturally occurring minerals like sodium carbonate and sodium sulfate becomes an attractive alternative for the activation of slag. Nevertheless, activation of slag solely with sodium carbonate and sodium sulfate generates longer setting ( $>3$ days) $[37,38]$ Hybrid activators can counterbalance this shortcoming to create a good balance between mechanical properties, cost, and environmental impact [39-41] However, the effect of hybrid activators on setting process of AASF remains unexplored.

Until now, conventional methods such as Vicat needle test on paste (EN 196-3) and the penetration test (ASTM C403) on mortar are mostly used to monitor the setting time of AASF. However, both methods destroy the microstructure at the point of penetration and do not allow monitoring the setting and hardening processes continuously. Evolution of ultrasonic wave velocity in cement and concrete has been commonly used to continuously monitor the percolation of the solid phases which cause dramatic changes in the ultrasonic wave behavior [42-46]. Longitudinal wave (P-wave) velocity is sensitive to the formation of hydrates and can characterize very early microstructural changes associated with setting. Few studies have recently used ultrasonic wave reflection method to monitor the setting time of metakaolinbased geopolymers [47-49] and found that geopolymers show a wide range of setting times depending on the chemical parameters such as geopolymer composition ( $\mathrm{Si} / \mathrm{Al}$ ratio), and type and concentration of the activator used. Another study has used the ultrasonic measurements to study the reaction progress of alkaliactivated metakaolin-slag blends and demonstrated that the rate of condensation is accelerated in metakaolin-slag blended systems compared to the individually activated systems [50]. Moreover, the elastic properties of metakaolin-based geopolymer at different $\mathrm{Si} /$ Al ratios have been evaluated by relating with the speed of both shear and longitudinal ultrasonic waves [51] Contrary to OPC, not much research has been carried out to investigate the setting process of AASF cements using ultrasonic measurements. Therefore, the objective of this study is to understand how the setting of AASF occurs using ultrasonic wave velocity based on transmission modes.

\section{Experimental program}

\subsection{Materials and mix proportion}

Ground granulated blast furnace slag and siliceous fly ash with a specific gravity of $2.92 \mathrm{~g} / \mathrm{cm}^{3}$ and $2.32 \mathrm{~g} / \mathrm{cm}^{3}$, respectively, were used as the primary materials. Their chemical composition determined via X-ray fluorescence (XRF) spectrometry, is given in Table 1.

Five AASF blends were prepared at $80: 20$ vol\% of slag-fly ash ratio by varying the type and the concentration of the alkaline solutions as listed in Table. 2. The alkaline solutions were prepared by dissolving solid sodium hydroxide, sodium carbonate and sodium sulfate in distilled water at least $24 \mathrm{~h}$ before use. The prepared sodium hydroxide solution was mixed with commercially available sodium silicate (39\%-40\% silicates in water) in order to achieve sodium silicate solution with alkali modulus $\left(\mathrm{SiO}_{2} / \mathrm{Na}_{2} \mathrm{O}\right)$ of 1.0. Simultaneously, the prepared sodium silicate solution of alkali modulus 1.0 was partially substituted ( $50 \mathrm{wt} \%$ ) with sodium carbonate and sodium sulfate solutions in order to obtain the molar ratios $\left(\mathrm{SiO}_{2} / \mathrm{Na}_{2} \mathrm{O}\right)$ of 0.7 and 0.6 . A solution-to-binder ratio (S/B) of 0.6 was fixed to all mixes. Paste mixes were prepared according to EN 196-3 [52], using a HOBART mixer. Small amounts of paste needed for calorimetry and XRD were prepared using overhead mixer at $750 \mathrm{rpm}$ for $2 \mathrm{~min}$.

\subsection{Experimental method}

\subsubsection{Crystalline phases}

The presence of different anions in the activating solution can lead to the formation of various reaction products which can affect the stiffness development of the matrix. Therefore, to better understand the influence of activator type on the setting behavior of AASF, first the reaction products were characterized using X-ray diffraction (XRD). Due to fact that the reaction phases formed in AASF cements are mainly X-ray amorphous, we aim here to identify the formation of possible crystalline phases due to presence of carbonate and sulfate anions in the activating solutions. XRD analysis was performed using Bruker D2 Phaser with $\mathrm{CuK} \alpha$ radiation $(\lambda=1.54 \AA$ ) operating at $30 \mathrm{kV}$ and $10 \mathrm{~mA}$. The samples were scanned over a range of $5^{\circ}-55^{\circ} 2 \theta$ and measured in step scan mode at $2 \mathrm{~s}$ per $0.02^{\circ} 2 \theta$.

\subsubsection{Vicat setting time}

The initial and final setting times were measured using an automatic recording Vicat needle apparatus according to EN 196-3 [52]. Initial setting is determined as the elapsed time between "zero time" (the time when the activating solution is mixed with the binder system) to the time at which the distance between the needle and the baseplate is $4 \pm 1 \mathrm{~mm}$. The final setting time is the elapsed time, measured from the "zero-time" to the time at which the needle penetrates less than $0.5 \mathrm{~mm}$ into the specimen. The reported results are the average values of two measurements. Since the standard consistency was not used in the preparation of paste samples, the setting time derived in this study could not be termed as standard setting time.

\subsubsection{Ultrasonic P-wave measurements}

A non-destructive ultrasonic wave transmission test is a wellestablished method to monitor the setting and hardening behavior of cementitious materials. An ultrasonic P-wave transmission test, according to EN 12504-4 [53], was performed by using IP-8 ultrasonic measuring instrument (Ultra Test) [54]. The device consists of a PC-connected controller unit allowing collections up to eight measuring cells. Each measuring cell is composed of high damping silicon mould, with an ultrasonic transmitter and receiver pair and a temperature sensor (Fig. 1). Four sound absorbers embedded into silicon mould helps to reduce the influence of waves travelling through the mould, by passing the paste sample. Measuring cells with a volume of $98 \mathrm{~cm}^{3}$ was used to monitor setting process in pastes. An ultrasonic pulse wave was transmitted every minute using a $30 \mathrm{kHz}$ transducer in order to study the setting and hardening behavior of alkali-activated slag/fly ash cements. By measuring the propagation time ' $t$ ' of the pulse wave over a path length ' $l$ ' or distance between transmitter and receiver, the P-wave transmission velocity $(v=l / t)$ through paste samples was computed.

The test is performed in a climate room with $20 \pm 1{ }^{\circ} \mathrm{C}$ and $65 \%$ $\mathrm{RH}$. To ensure an optimal contact quality and an improved signalto-noise ratio, as well as to avoid demoulding problems, a thin 
Table 1

Chemical composition (by mass \%) of slag and fly ash.

\begin{tabular}{|c|c|c|c|c|c|c|c|c|}
\hline Materials & $\mathrm{SiO}_{2}$ & $\mathrm{Al}_{2} \mathrm{O}_{3}$ & $\mathrm{Fe}_{2} \mathrm{O}_{3}$ & $\mathrm{CaO}$ & $\mathrm{MgO}$ & $\mathrm{SO}_{3}$ & $\mathrm{MnO}$ & $\mathrm{K}_{2} \mathrm{O}$ \\
\hline Slag & 36.190 & 12.410 & 0.600 & 39.80 & 7.250 & - & 0.320 & 0.490 \\
\hline Fly ash & 57.440 & 26.130 & 6.290 & 2.43 & 1.49 & 0.830 & 0.052 & 2.900 \\
\hline Materials & $\mathrm{TiO}_{2}$ & $\mathbf{V}_{2} \mathbf{O}_{5}$ & SrO & $\mathrm{ZrO}_{2}$ & $\mathrm{Cr}_{2} \mathrm{O}_{3}$ & $\mathbf{S}$ & BaO & $\mathrm{Na}_{2} \mathrm{O}$ \\
\hline Slag & 1.070 & 0.019 & 0.092 & 0.049 & - & 1.530 & 0.066 & - \\
\hline Fly ash & 1.340 & 0.048 & 0.135 & 0.050 & 0.018 & - & 0.138 & 0.450 \\
\hline
\end{tabular}

Table 2

Mixture proportion of alkali-activated slag-fly ash blends.

\begin{tabular}{|c|c|c|c|c|c|c|}
\hline \multirow[t]{2}{*}{ Mix ID } & \multicolumn{2}{|c|}{ Sodium Silicate } & \multirow{2}{*}{$\begin{array}{l}\text { Sodium Carbonate } \\
\mathrm{Na}_{2} \mathrm{O}[\%]\end{array}$} & \multirow{2}{*}{$\begin{array}{l}\text { Sodium Sulfate } \\
\mathrm{Na}_{2} \mathrm{O}[\%] \\
\end{array}$} & \multirow[t]{2}{*}{ Modulus $\mathrm{M}_{\mathrm{s}}=\left(\mathrm{SiO}_{2} / \mathrm{Na}_{2} \mathrm{O}\right)$} & \multirow[t]{2}{*}{ pH Value } \\
\hline & $\mathrm{SiO}_{2}[\%]$ & $\mathrm{Na}_{2} \mathrm{O}[\%]$ & & & & \\
\hline SS-1.0 & 8.30 & 8.30 & - & - & 1.0 & 14.70 \\
\hline SC-0.7 & 4.15 & 4.15 & 1.80 & - & 0.7 & 14.40 \\
\hline SC-0.6 & 4.15 & 4.15 & 2.80 & - & 0.6 & 14.40 \\
\hline SSu-0.7 & 4.15 & 4.15 & - & 1.80 & 0.7 & 14.40 \\
\hline SSu-0.6 & 4.15 & 4.15 & - & 2.80 & 0.6 & 14.40 \\
\hline
\end{tabular}

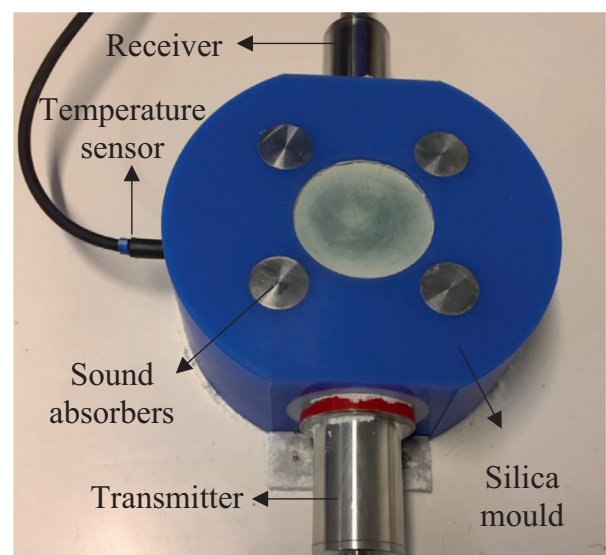

Fig. 1. Ultrasonic pulse wave transmission unit of the measurement equipment.

layer of silica grease was applied inside the mould and the contact surface of the ultrasonic testers. To avoid sample drying, which can lead to a loss of the contact of the samples with ultrasonic testers, the samples were sealed with an inner layer of plastic foil and an outer layer of aluminium foil, and their top surface was covered with a glass plate. The average of two measurements were taken for each mix composition.

\subsubsection{Isothermal calorimeter}

The heat release was measured on paste samples using an isothermal heat conduction calorimetry (TAM air device TA Instruments) at $20^{\circ} \mathrm{C}$. The raw materials were first mixed with the alkaline solutions externally using an overhead mixer at $750 \mathrm{rpm}$ for $2 \mathrm{~min}$ and then around $8 \pm 0.5 \mathrm{~g}$ of the mixed paste sample was transferred into a small ampoule and loaded into the calorimeter channels. The heat evolution results are normalized by mass of the binder (slag + fly ash) materials. The calorimetry results are well explained in our previous studies [55,56].

\section{Results and discussion}

\subsection{Crystalline phases}

The XRD patterns of raw materials and AASF pastes are shown in Fig. 2. While slag is mainly amorphous, fly ash contains some crystalline phases of mullite and quartz along with the amorphous

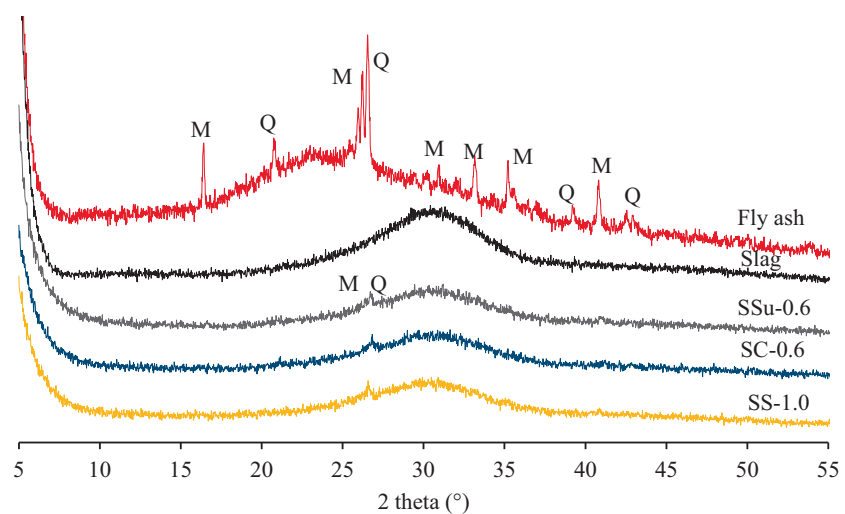

Fig. 2. X-ray diffractograms of precursors and AASF pastes cured for $5 \mathrm{~h}$. Peaks marked are Mullite (M) and Quartz (Q).

phase. Previous studies on alkali-activated slag [37,39,57] have reported that presence of $\mathrm{CO}_{3}^{2-}$ and $\mathrm{SO}_{4}^{2-}$ ions in the solution would lead to the formation of calcite and ettringite, respectively, at early hours. However, our XRD results do not show carbonate and ettringite phases in the samples activated with sodium carbonate (SC) and sodium sulfate (SSu), respectively. This raises the question of the role of carbonate and sulfate ions in the activating solutions during early hours of reaction, which needs to be further investigated. Also, no clear diffraction peak corresponding to C-A-S-H type gels is observed after $5 \mathrm{~h}$ of reaction. As the $\mathrm{pH}$ value of the pore solution is around 14 , the concentration of the dissolved Ca ions in the pore solution will be very low due to its less solubility at higher alkalinity [58]. As a result, the Si-rich C-A-S-H type gels are formed during early hours of reaction, which is difficult to identify via XRD.

\subsection{Vicat setting times}

The Vicat setting times of the studied AASF pastes are shown in Fig. 3. In OPC-based materials, the final setting time is defined as the time required to completely lost its plasticity or stiffening of paste without significant development of strength, which usually occurred at around 6-10 h. However, for sodium silicateactivated AASF, it takes only around $90 \mathrm{~min}$. With the incorporation of sodium carbonate and sodium sulfate solutions, the initial setting time slightly increases from $45 \mathrm{~min}$ to $65 \mathrm{~min}$, while the final setting time notably increases from $90 \mathrm{~min}$ to $310 \mathrm{~min}$. Both 


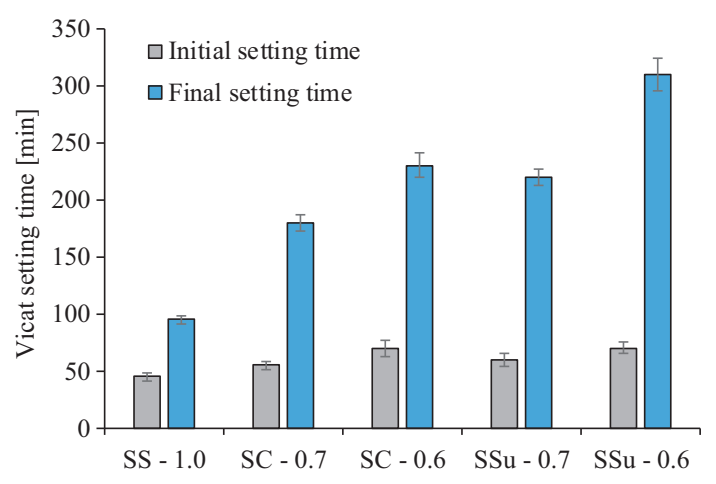

Fig. 3. Vicat Setting times of AASF pastes.

initial and final setting times increase with an increase in the concentration of sodium carbonate (SC-0.6) and sodium sulfate activators (SSu-0.6). Samples incorporating sodium sulfate exhibit longer setting times compared to those with sodium carbonate at the same alkali content $\left(\mathrm{Na}_{2} \mathrm{O}\right)$. This suggests that the nature of anions present in the activator has a decisive role in the setting behavior of AASF cements.

\subsection{Evolution of ultrasonic P-wave velocity}

Typical ultrasonic P-wave velocity (UPV) curve and its first derivative curve of AASF paste (SS-1.0) are illustrated in Fig. 4 and Fig. 5, respectively. By relating UPV curves with isothermal calorimetry heat flow, the UPV curve can be divided into five characteristic stages as follows: dissolution stage (stage I), condensation stage (stage II), induction stage (stage III), acceleration stage (stage IV), and the deceleration stage (stage V). Immediately after mixing and moulding, the measured ultrasonic velocity of the fresh paste is lower than that of the alkali solution (1450-1600 m/s) and air $(340 \mathrm{~m} / \mathrm{s})$. Since fresh paste is a liquid suspension including slag and fly ash particles, the solution-air phase acts as a dominating factor that determines the ultrasonic velocity. Although a fully connected pore solution isolates the suspended solid particles from each other, the ultrasonic velocity in the fresh paste is lower than the velocity of the solution. The initial value of the P-wave velocity in AASF pastes is around $300 \mathrm{~m} / \mathrm{s}$ (Fig. 4a). A similar value is reported for OPC in the literature [59-61]. It is suggested that the presence of air bubbles in the mixing solution and tiny airbubbles entrapped into the paste during mixing can result in a lower value of ultrasonic velocity [62-65] Additionally, the dispersion of solid particles in the solution can lead to a lower ultrasonic velocity, as the travel time of the ultrasonic wave increases with an increase in the elongated length of the wave-path due to suspended grains [66].

As clearly observed in Fig. 4a, the ultrasonic velocity during the first dissolution stage decreases at a very slow rate. This stage corresponds to the pre-induction period of heat flow curves, which is assigned to the wetting and dissolution of slag and fly ash particles, hydrolysis of silicate and aluminate species and subsequent formation of either aluminosilicate oligomers or monomers in the solution and their complexation with calcium and sodium [67-69]. By correlating the ultrasonic velocity curves with the isothermal calorimetry heat flow curves, the first dissolution stage in UPV curves can be explained as follows: the decrease in the ultrasonic velocity during the first dissolution stage can be attributed to the formation of aluminosilicate oligomers with cavities that accommodate alkaline cations as charge imbalance generated by replacing $\mathrm{Al}^{3+}$ with $\mathrm{Si}^{4+}$ ions [70,71]. Simultaneously, the hydrolysis of dissolved aluminosilicate oligomers results in the formation of more smaller aluminosilicate oligomers and/or monomers in solution can also lower the ultrasonic velocity. In other words, the presence of more Si-Al units with cavities and their reaction complexes with dissolved $\mathrm{Ca}^{2+}$ and $\mathrm{Na}^{+}$ions in the solution [72],in suspension, creates less space for the waves to propagate, thereby lowering the value of ultrasonic velocity during the first dissolution stage. The formation of aluminosilicate oligomers and/or monomers in the solution implies that the reaction mechanism during the first hours in AASF is a 'through-solution' precipitation that contrasts with the 'topotactic' growth of C-S-H gel in OPCbased materials $[73,74]$. Additionally, the decrease in the ultrasonic velocity may also partially result from un-reacted fly ash with a hollow structure, after the dissolution of small fly ash particles that are trapped inside the larger hollow fly ash particles [75].

After around $15-25 \mathrm{~min}$, the solid percolation path starts to develop and leads to the propagation of wave through the solid phase instead of through liquid phase, which causes a sudden increase in the ultrasonic velocity, as shown in Fig. 4a. In other words, the propagation of the ultrasonic velocity increases because the system changes from a suspension state to a solid network frame, as defined by the first inflection point IP1 (maximum of first derivative curve) in this study (Fig. 5a). Also, the ultrasonic velocity already starts to increase rapidly in the pre-induction period of heat flow curves (Fig. 4). This remarkable acceleration of ultrasonic velocity in the pre-induction period can be explained by two phenomena. Firstly, the previously formed aluminosilicate oligomers and/or monomers in solution may undergo continuous condensation reactions and form large aluminosilicate structural units near the particle surface of slag and fly ash [47], which leads to the
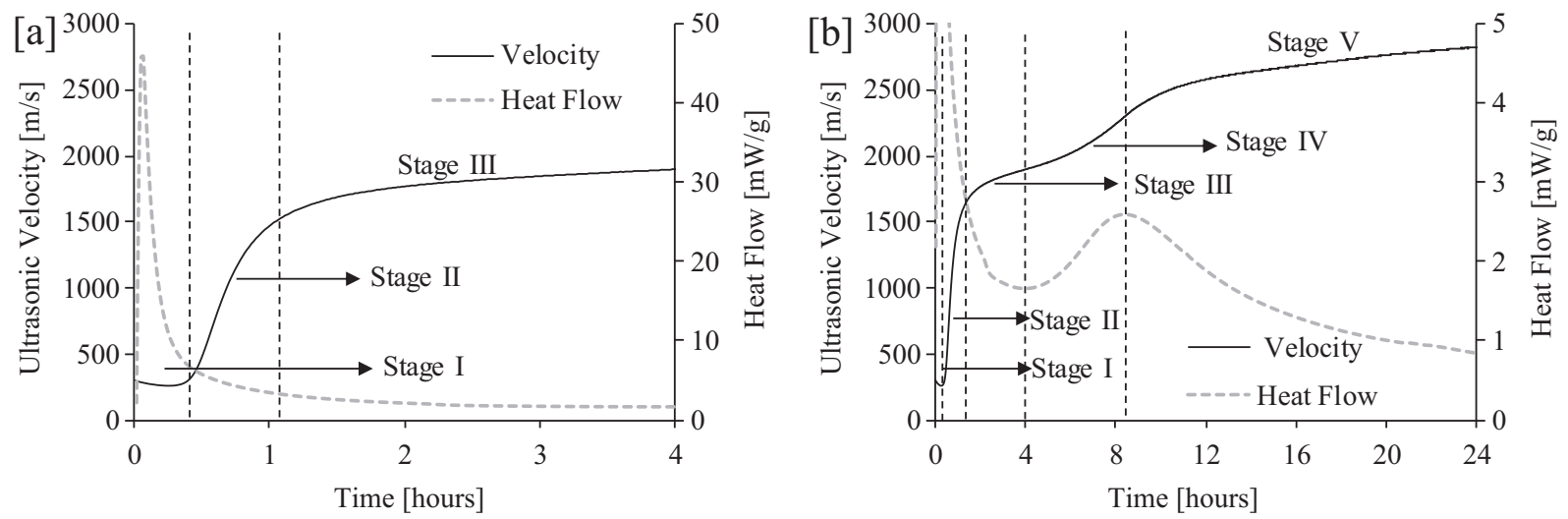

Fig. 4. Ultrasonic P-wave velocity $\mathrm{V}_{\mathrm{s}}$ isothermal calorimetry heat flow curves of AASF paste [SS-1.0]; first $4 \mathrm{~h}$ [a], up to $24 \mathrm{~h}$ [b]. 

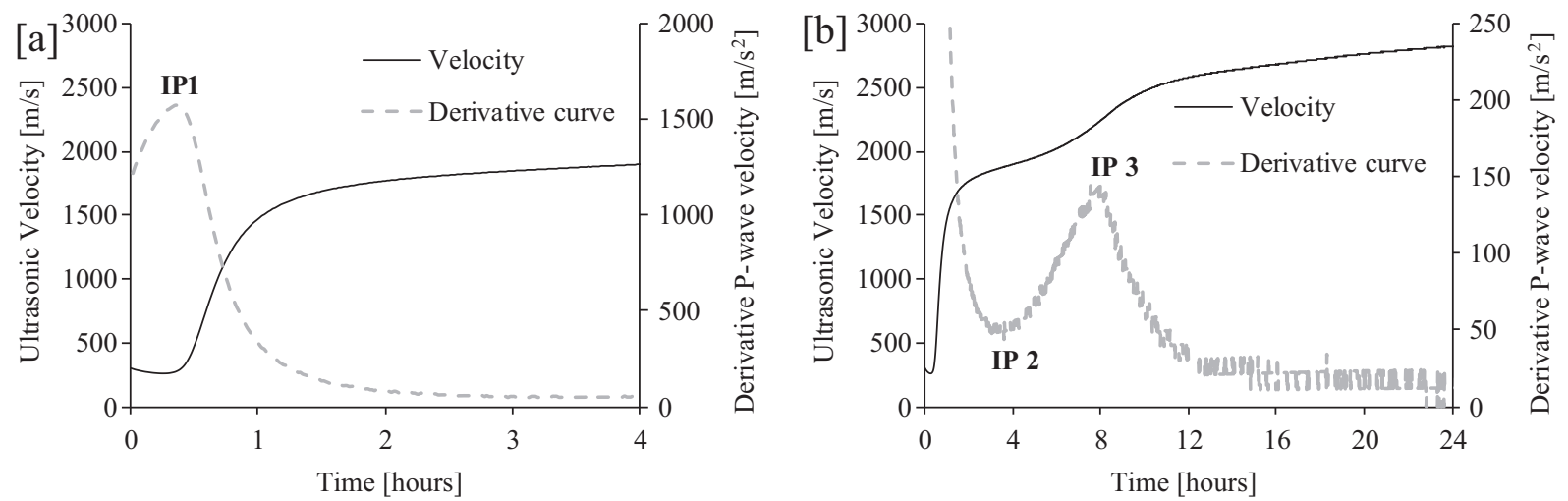

Fig. 5. Ultrasonic P-wave velocity and its first derivative curve of AASF paste [SS-1.0]; first $4 \mathrm{~h}$ [a], up to $24 \mathrm{~h}$ [b].

development of interconnected solid phases and increase in ultrasonic velocity. Secondly, the formation of reaction products upon contact with the dissolved $\mathrm{Ca}^{2+}$ ions from slag and the anions of the activator, changes the material from liquid suspension to a porous solid state [34]. The formation of these reaction products fills the pore spaces originally occupied by the alkaline solution and increases the solid volume fraction, which contributes to the significant rise in ultrasonic velocity during the second stage. This reaction and corresponding reaction products formed in the preinduction period plays an important role in the initial setting behaviour of the AASF. This rapid increase in the ultrasonic velocity during the condensation stage of UPV curves and per-induction period of heat flow curve indicates that the reaction mechanism of AASF systems is composed of dissolution followed by precipitation and rapid condensation between initially formed aluminosilicate oligomers and/or monomers. This early increase of the ultrasonic velocity in the pre-induction period can also be partially explained by some physical phenomena: air bubble migration to the surface due to bleeding, workability loss due to intake of solution by initial chemical reactions and densification of the internal structure by settling of the particles due to gravity, causing a mechanical bounding between particles [63].

During the third stage, only a small increase in ultrasonic velocity is observed, corresponding to the induction period of heat flow curves, as shown in Fig. 4b. Previous studies have reported that the induction period in AASF could be due to the dilution effect caused by the formation of $\mathrm{Si}-\mathrm{Al}$ rich layer on the surface of unreacted particles or the time needed to rise to a critical concentration of ions in order to form more reaction products [76,77] Although almost no reaction takes place in the induction period, the gradual increase in ultrasonic velocity can be attributed to the formation of more interconnected network structure by polycondensation reaction at solid-liquid interface and/or between initial reaction products. In other words, two functional silicate groups attached to the adjacent aluminosilicate structural units can be brought into contact to form a more interconnected solid-phase network. As a result, the ultrasonic velocity increases slowly until the end of the induction stage, defined by the second inflection point (IP2) in this study as shown in Fig. 5b. After that, the ultrasonic velocity increases gradually up to the third inflection point (IP 3), which is associated to the end of the acceleration period of heat flow curve (Fig. 4b). As more reaction products are formed and linked to the connected solid phases, the total solid volume fraction increases and leads to a gradual increase in the ultrasonic velocity during the acceleration stage (stage IV). During the deceleration stage, a slight increase in the ultrasonic velocity is recorded and it reaches a plateau (Fig. 4b). The heat flow curves correspond well with the first derivative P-wave velocity curve and temperature measurement by the ultrasonic device as shown in Fig. 6 and Fig. 7, respectively.

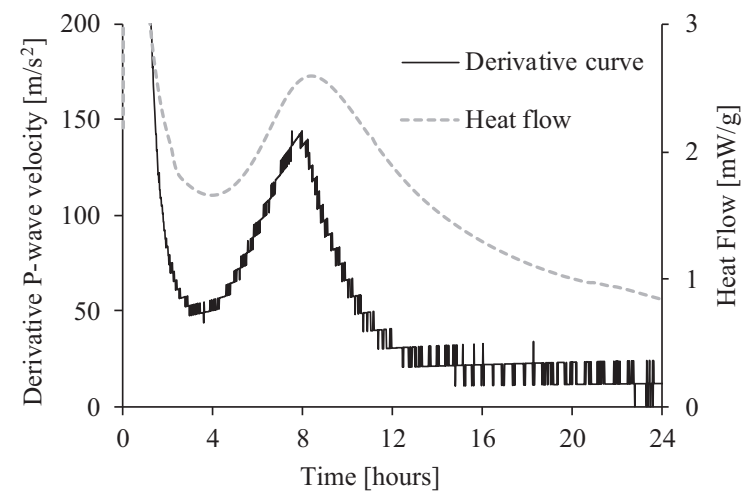

Fig. 6. Derivative P-wave velocity $V_{s}$ heat evolution curve from isothermal calorimetry for SS-1.0.

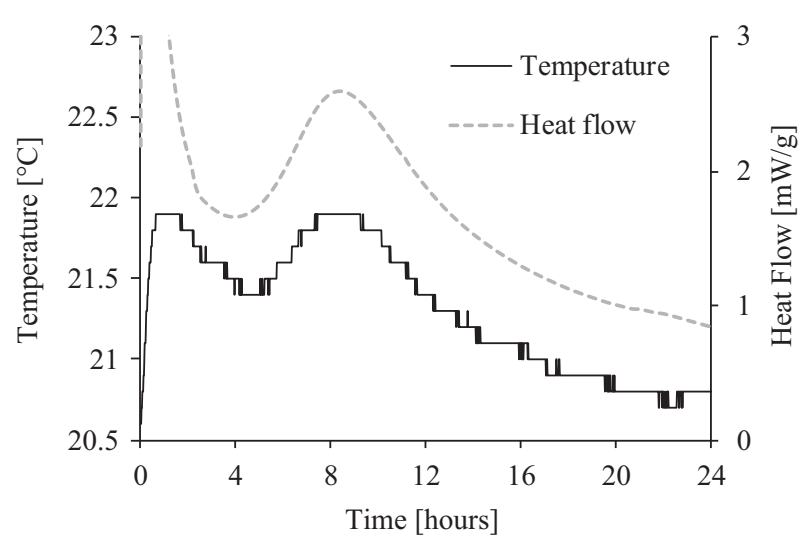

Fig. 7. Temperature evolution curve from ultrasonic measurement $\mathrm{V}_{\mathrm{s}}$ heat evolution curve from isothermal calorimetry for SS-1.0.

\subsection{Ultrasonic measurements on AASF paste}

The ultrasonic P-wave velocity (UPV) curves of all studied AASF pastes show a similar trend composed of five stages (Fig. 8). During the first dissolution stage, the ultrasonic velocity gradually decreases in all samples. This indicates that, irrespective of anions present in the activator, aluminosilicate oligomers with cavities are favored at early hours of reaction. Since the $\mathrm{pH}$ value of all alkaline solutions used in this study is $>14.0$ (Table. 2), the concentration of dissolved $\mathrm{Al}$ and $\mathrm{Si}$ increases, and the concentration of $\mathrm{Ca}$ ions decreases in the pore solution [58]. In sodium silicate activation (SS-1.0), the $\mathrm{SiO}_{4}^{4-}$ anions present in the activator solutions react 

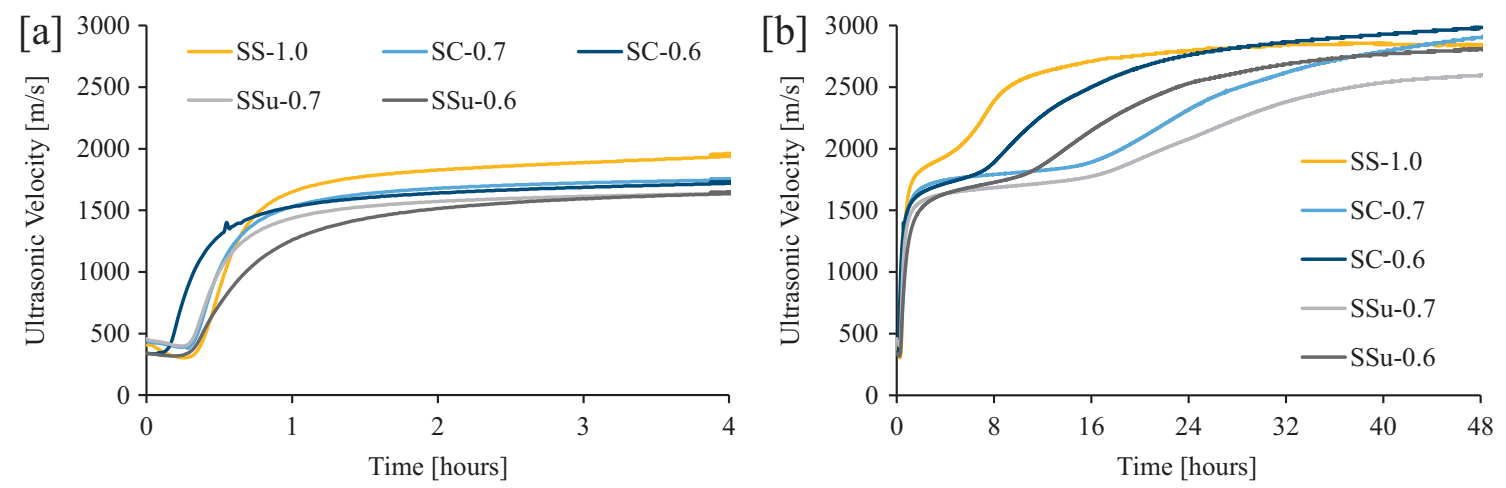

Fig. 8. Ultrasonic P-wave velocity curves of AASF pastes; first $4 \mathrm{~h}$ [a], up to $48 \mathrm{~h}$ [b].

more readily with the dissolved $\mathrm{Al}$ ions to form aluminosilicate oligomers and/or monomers within the first few minutes of reaction. The samples with sodium carbonate (SC) also favour the formation of aluminosilicate structural units at early hours as the concentration of dissolved calcium ions in the solution is very low to form calcite phases. While in samples with sodium sulfate (SSu), the decrease in the ultrasonic velocity associated with the formation of aluminosilicate units indicates that the dissolved $\mathrm{Al}$ ions react with $\mathrm{SiO}_{4}^{4-}$ ions in the pore solution rather with the $\mathrm{SO}_{4}^{2-}$ anions provided from the activating solutions.

During the condensation stage, there is a steep increase in the P-wave velocity in all samples, regardless of anions present in the activating solution. This is mainly attributed to the condensation reaction between the initially formed aluminosilicate units as explained above. Moreover, this behavior is also assigned to the formation of reaction products like C-A-S-H [35,78], calcite $[39,57,79]$, and ettringite $[37,80]$ when the concentration of dissolved $\mathrm{Ca}^{2+}$ ions increases over time and reacts with the activator anions $\mathrm{SiO}_{4}^{4-}, \mathrm{CO}_{3}^{2-}$ and $\mathrm{SO}_{4}^{2-}$ respectively. However, no clear diffraction peaks corresponding to the formation of these reaction products are found in the XRD patterns (Fig. 2) during early hours of reaction in studied AASF samples. These results suggest that a sufficient amount of $\mathrm{Ca}^{2+}$ ions has not been released yet by the slag to form these reaction products, due to its low solubility in high alkaline conditions $(\mathrm{pH}>14)$. On the other hand, some studies on sodium sulfate activation [81-84] have reported that the presence of high amounts of $\mathrm{OH}^{-}$ions (high $\mathrm{pH}$ value) affects the morphology and crystallinity of ettringite phases formed at early hours. At high $\mathrm{pH}$ value $(\mathrm{pH}>13.2)$, the ettringite formed is almost X-ray amorphous and difficult to identify in the XRD patterns [85]. Further investigation using scanning electron microscopy and ${ }^{27} \mathrm{Al}$ NMR is necessary here to elucidate the presence of ettringite in the studied AASF compositions.

During induction stage, the ultrasonic velocity increases rapidly for the sample activated with sodium silicate (SS-1.0). Since the increase in the ultrasonic velocity is associated to the connected solid volume fraction, the solid network seems to develop faster with higher $\mathrm{SiO}_{2}$ content in the activator. This behavior can be attributed to a high degree of silica condensation reaction, forming a Si-rich gel and subsequently reacting with the dissolved $\mathrm{Ca}^{2+}$ ions to form more C-A-S-H gel with an increased connected solid volume fraction. While in samples incorporated with sodium carbonate and sodium sulfate, a longer induction stage is observed due to the low concentration of $\mathrm{OH}^{-}$ions (Table. 2) resulting in lower rate of reaction. An increase in concentration of sodium carbonate (SC0.6 ) and sodium sulfate (SSu-0.6) solutions, results in a more rapid evolution of ultrasonic velocity. This suggests that an increase in alkali content $\left(\mathrm{Na}_{2} \mathrm{O}\right)$ enhances the dissolution of slag and consequently increases the reaction products precipitation. In the sample activated with sodium silicate (SS-1.0), a decrease in ultrasonic velocity was noticed over time. This is likely due to a large autogenous shrinkage behavior in SS-1.0 [86], which leads to the loss of contact between ultrasonic probes and paste sample.

\subsection{Comparison between Vicat setting times and ultrasonic measurements}

Two strategies are often used to analyze the setting behavior of cementitious materials by using ultrasonic velocity measurement. The first one is based on the time to reach a specific value or range of ultrasonic velocity. The second approach adopts identification of the characteristic points or inflection points in the ultrasonic curves, corresponding to the distinct changes in microstructure development. In order to accurately determine the inflection points on the ultrasonic curves, smoothing of the curves is recommended by using mathematical modelling. Among the different mathematical models available in the literature [63,87,88], a triexponential function (Eq. (1)) is the most appropriate function for fitting the ultrasonic P-wave curves at early ages in AASF cements as given below:

$V_{p}(t)=\sum_{i=1}^{3} a_{i} \cdot \exp \left(-\left(\frac{b_{i}}{t}\right)^{c_{i}}\right)+d$

where $a_{i}$ is the amplitude, $b_{i}$ is the time parameter, $c_{i}$ is the shape parameter and $d$ is the baseline parameter. When we compare Vicat setting times with ultrasonic velocity curves (Fig. 9), we get initial setting time corresponding quite well with the end of the condensation stage of the ultrasonic velocity curves, where a rigid framework of connected solid phases is formed as a result of continuous condensation reaction between initial formed aluminosilicate units. However, the final setting time cannot be determined from the inflection point approach in the same way as described for OPC-based materials in [54,66,89]. An alternative approach based on ultrasonic P-wave velocity can be used to define the initial and final setting time of AASF as illustrated in Table. 3. The initial and final setting times of studied AASF can be determined by the velocity ranges: $1450-1550 \mathrm{~m} / \mathrm{s}, 1650-1750 \mathrm{~m} / \mathrm{s}$, respectively. Similar velocity ranges have been proposed in literature to estimate the initial and final setting times of cement paste at water-to-binder ratio of $0.5[66,90]$.

Both initial and final setting time of AASF occur before the formation of massive reaction products in the acceleration stage of the ultrasonic measurements (Fig. 9). This is in contrast to Portland cement pastes where the initial and final setting time appear in the acceleration period where $\mathrm{C}_{3} \mathrm{~S}$ hydrates to $\mathrm{C}-\mathrm{S}-\mathrm{H}$ and portlandite. This implies that setting process in AASF cannot be solely attributed to the formation of C-(A-)S-H type gel, like in Portland cements. 

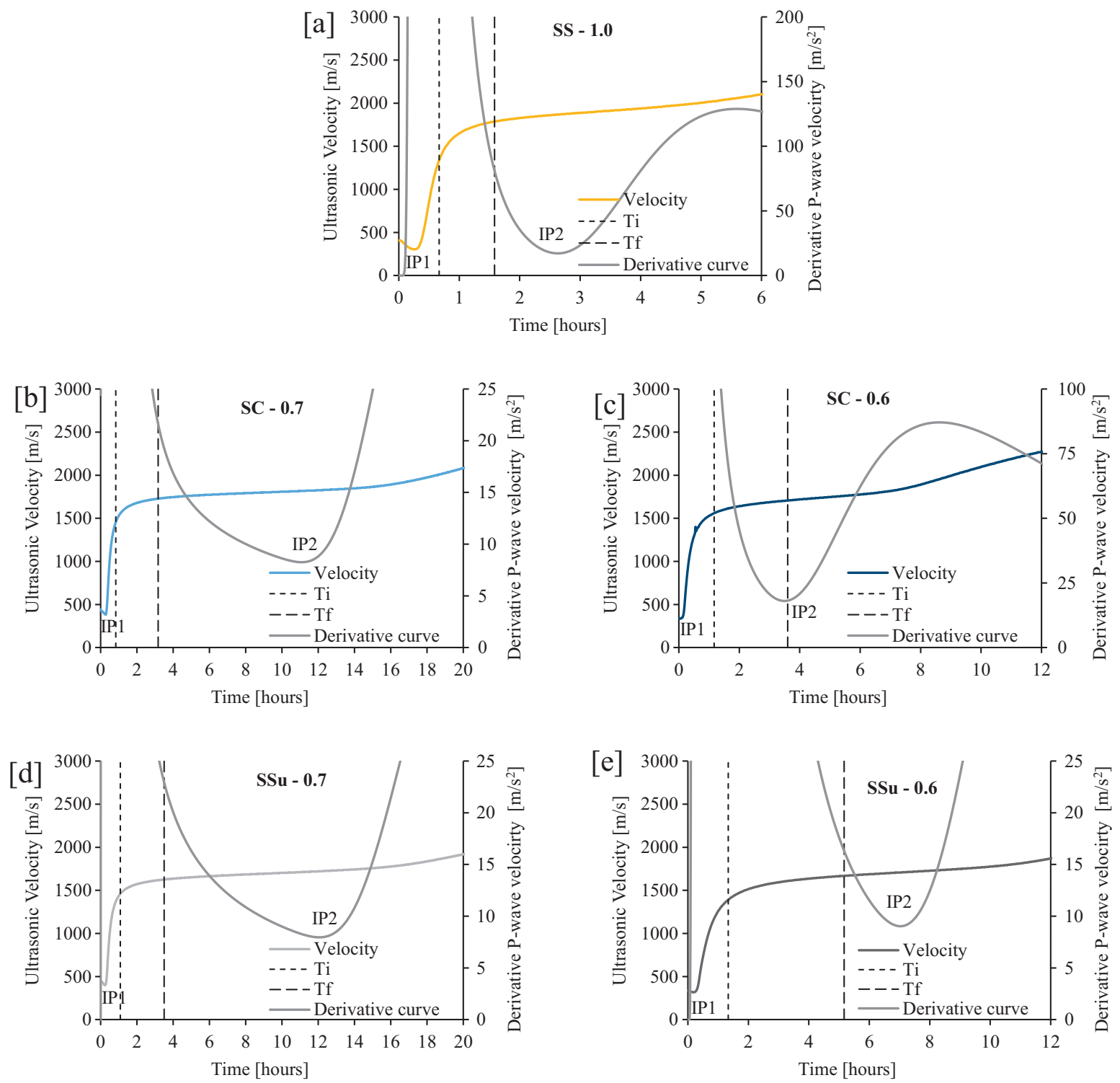

Fig. 9. Comparison between the ultrasonic measurements and Vicat setting times of AASF cements; $T_{i}-$ Vicat initial setting time, $T_{f}-$ VicatFinal setting time.

Table 3

Ultrasonic P-wave velocity corresponding to Vicat setting times of studied AASF.

\begin{tabular}{lll}
\hline Mix & $\begin{array}{l}\text { Ultrasonic P-wave velocity at } \\
\text { initial setting time }[\mathrm{m} / \mathrm{s}]\end{array}$ & $\begin{array}{l}\text { Ultrasonic P-wave velocity at } \\
\text { final setting time }[\mathrm{m} / \mathrm{s}]\end{array}$ \\
\hline SS -1.0 & 1465 & 1650 \\
SC -0.7 & 1525 & 1725 \\
SC -0.6 & 1550 & 1715 \\
SSu -0.7 & 1460 & 1650 \\
SSu -0.6 & 1440 & 1680 \\
\hline
\end{tabular}

\subsection{Initial setting time:}

With regard to the ultrasonic measurements, the initial setting time was found to appear in the condensation stage (Fig. 9), corresponding to the pre-induction period of heat flow curves. As explained above, the condensation stage in ultrasonic measurement can be attributed to the continuous condensation reaction between the aluminosilicate units and formation of initial reaction products with no or little influence on setting process. In Fig. 8, we observe that in samples incorporating sodium carbonate and sodium sulfate no significant changes are recorded during the condensation stage of the ultrasonic measurements. This could explain the marginal differences in initial setting time of these samples (Fig. 3). In other words, regardless of anions present in the activator, all samples favour the formation of aluminosilicate units during the first hours of reaction and leads to initial setting process as a result of condensation reaction.

\subsection{Final setting time:}

Vicat final setting time of AASF occurs during the induction period of ultrasonic measurements, where the velocity increases slowly due to polycondensation reaction at solid-liquid interface and/or between adjacent aluminosilicate structural units (Fig. 9). The Vicat test results reveal that the final setting time of sodium silicate activated samples is significantly delayed by incorporating sodium carbonate and sodium sulfate solutions. This is mainly attributed to the decrease in the concentration of $\mathrm{SiO}_{4}^{4-}$ ions in the activating solution (Table. 2). Also, the partial substitution of sodium silicate with sodium carbonate and sodium sulfate solutions reduces the $\mathrm{pH}$ value of the activating solution (Table. 2) and consequently, decreases the concentration of the dissolved $\mathrm{Si}$ 
ions in pore solution due to a decrease in its solubility at lower $\mathrm{pH}$. The decrease in the concentration of $\mathrm{Si}$ ions in the pore solution suppresses the degree of Si polycondensation and results in longer setting times in samples activated with sodium carbonate and sodium sulfate. In Fig. 3, it is observed that the final setting time increases with increasing concentration of sodium carbonate and sodium sulfate solutions (SC-0.6 and SSu-0.6). The presence of more $\mathrm{CO}_{3}^{2-}$ and $\mathrm{SO}_{4}^{2-}$ ions in the pore solution, which are likely not involved in the formation of reaction products, are assumed to decelerate the polycondensation reaction between the adjacent aluminosilicate structural units and lead to longer setting times. Further study is needed to support this assumption. At equal replacement of sodium silicate with sodium carbonate and sodium sulfate, the final setting is lower for samples with sodium carbonate (Fig. 3). This can be explained by the lower induction time and faster precipitation of reaction products in samples with sodium carbonate than samples with sodium sulfate, as observed in Fig. 8b.

\subsection{Comparison between Vicat setting times and reaction degree}

Setting generally occurs when a specific microstructure development or reaction degree has occurred [91]. Therefore, the comparison between Vicat setting times and reaction degree is meaningful. In general, the degree of reaction can be represented by the ratio of the cumulative heat release at a time " $t$ " of reaction process to the total heat release at infinite time $Q_{\infty}$ (Eq. (2)) [92]. The main advantage of using the cumulative heat release to determine the reaction degree is that it is a continuous measurement starting from the mixing time. However, measuring the ultimate heat release $Q_{\infty}$ is virtually impossible since the accuracy of the measuring heat release is uncertain at this point. Recent study has compared the ultrasonic velocity curves with isothermal calorimetry of alkali-activated slag by relating the ultimate heat release $Q_{\infty}$ to the total heat release after 7 days [50]. Another study [93] assumes that the ultimate heat release is equal to the heat release that occurs at a heat flow of $0.3 \mathrm{~W} / \mathrm{g}$, which is not always the case. Therefore, an exponential model suggested by Freisleben-Hansen and Pedersen (FHP model) [94,95] is adopted in this study to compute the ultimate heat release $Q_{\infty}$ (Eq. (3)). Due to inability of this model for the multi-curvature heat flow evolutions in AASF [86], an additional parameter ' $\mathrm{Q}_{2}$ ' is introduced as described in [92], in order to find the unknown value of the ultimate heat release (Eq. (4)).

$\alpha(t)=\frac{Q(t)}{Q_{\infty}}$

$Q(t)=Q_{1} \cdot \exp \left(\left[\frac{-\tau_{1}}{t}\right]^{\beta_{1}}\right)+Q_{2} \cdot \exp \left(\left[\frac{-\tau_{2}}{t}\right]^{\beta_{2}}\right)$

$Q_{\infty}=Q_{1}+Q_{2}$

In the above exponential equations, $\alpha(t)$ is degree of reaction at equivalent age $t, Q(t)$ is the cumulative heat release at time $t, Q_{\infty}$ is the ultimate heat release at infinite time, $\tau$ and $\beta$ are the time and shape parameters respectively. Fig. 10 illustrates the FHP model fitting of the cumulative heat release curves of sodium silicateactivated slag/fly ash blend (SS-1.0). Parameters of the FHP model for the studied AASF mixes is given in Table. 4 .

The relation between the calculated reaction degree and the Vicat setting times of AASF pastes is summarized in Table. 5. The reaction degree of around $2.1-3.2 \%$ and $3.5-4.5 \%$ corresponds to the formation of critical volume fraction of reaction products, resulting in initial and final setting in AASF, respectively. The difference in the reaction degree corresponding to Vicat setting times in between studied AASF pastes is attributed to the polycondensa-

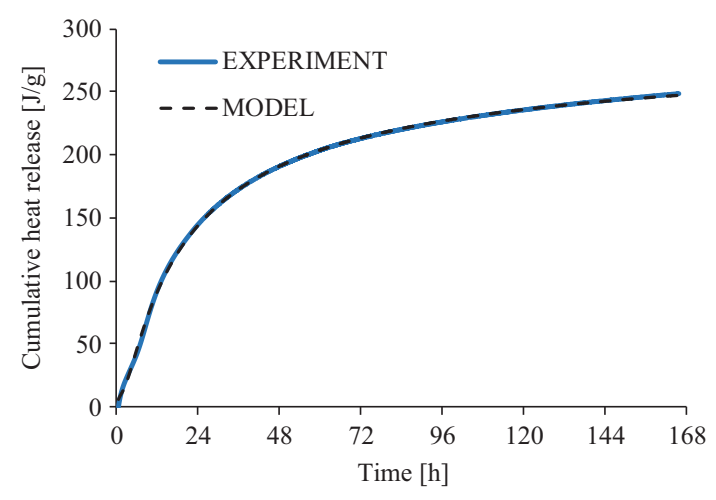

Fig. 10. FHP model fitting of cumulative heat release curve of SS-1.0.

tion degree between initially formed reaction products. Nevertheless, further study is needed to validate this model using ${ }^{29} \mathrm{Si} \mathrm{NMR}$ and scanning electron microscopic analysis.

\subsection{Reaction progress in AASF from the evolution of UPV}

Based on the evolution of ultrasonic velocity curves, the reaction process of AASF can be described as a combination of four stages: dissolution-hydrolysis (stage A), precipitationcondensation (stage B), polycondensation (stage C), and further reaction with advantaged time of curing (stage $D$ ). Stage A represents the initial stage of reaction, in which the dissolution and hydrolysis of dissolved species occur simultaneously and form aluminosilicate oligomers and monomers in solution. Stage B starts with a condensation reaction between the aluminosilicate species to form large units near the surface of slag and fly ash particles. Simultaneously, the formation of initial reaction products due to the reaction between dissolved $\mathrm{Ca}^{2+}$ from slag and the anions from the activator increases the connected solid volume fraction. Stage $C$ is assigned to the polycondensation reaction between the previously formed reaction products, as the aluminosilicate units formed near the surface of slag and fly ash particles act as a barrier and temporarily suppress the further dissolution to form new reaction products. Stage D corresponds to the further growth of the reaction products, with an increase in the concentration of the dissolved ions in the solution rather than the saturated concentration of the reaction products.

\section{Conclusion}

This study aims to understand the setting process of AASF using ultrasonic P-wave velocity measurements. The influence of incorporating sodium carbonate and sodium sulfate on the setting process of sodium silicate-activated AASF is discussed. Based on the results presented, the following conclusions can be drawn:

- Based on the evolution of ultrasonic P-wave velocity, the complex chemical reactions are composed of dissolution followed by precipitation and rapid polycondensation, and densification by forming more reaction products.

- The partial substitution of sodium silicate with sodium carbonate and sodium sulfate has no significant influence on initial setting time, while the final setting time increases significantly.

- The setting is mainly associated to the polycondensation reaction between the aluminosilicate units precipitated near the particle surface.

- The ultrasonic P-wave velocity range of around 1450-1550 m/s and $1650-1750 \mathrm{~m} / \mathrm{s}$ corresponds well with the initial and final setting of investigated AASF, respectively. 
Table 4

Parameters of the FHP model for AASF pastes.

\begin{tabular}{|c|c|c|c|c|c|c|c|}
\hline Mix & $\mathrm{Q}_{1}$ & $\mathrm{Q}_{2}$ & $\tau_{1}$ & $\tau_{2}$ & $\beta_{1}$ & $\beta_{2}$ & $\mathrm{Q}_{\infty}$ \\
\hline SS-1.0 & 34.50 & 262.0 & 2.30 & 17.00 & 0.37 & 0.75 & 296.5 \\
\hline SC- 0.7 & 22.70 & 207.5 & 2.25 & 26.90 & 0.19 & 1.33 & 230.2 \\
\hline SC-0.6 & 16.80 & 228.0 & 2.77 & 17.95 & 0.18 & 1.00 & 245.0 \\
\hline SSu-0.7 & 23.20 & 207.1 & 1.80 & 30.50 & 0.22 & 1.30 & 230.3 \\
\hline SSu-0.6 & 16.50 & 227.0 & 1.32 & 20.00 & 0.19 & 1.08 & 243.5 \\
\hline
\end{tabular}

Table 5

Comparing Vicat setting times with the calculated reaction degree.

\begin{tabular}{lll}
\hline Mix & $\begin{array}{l}\text { Reaction degree at initial } \\
\text { setting time [\%] }\end{array}$ & $\begin{array}{l}\text { Reaction degree at final } \\
\text { setting time [\%] }\end{array}$ \\
\hline SS -1.0 & 2.5 & 3.8 \\
SC -0.7 & 3.0 & 4.0 \\
SC -0.6 & 2.1 & 3.5 \\
SSu -0.7 & 3.2 & 4.5 \\
SSu -0.6 & 2.4 & 4.2 \\
\hline
\end{tabular}

\section{CRediT authorship contribution statement}

Siva Uppalapati: Conceptualization, Methodology, Software, Investigation, Writing - original draft, Writing - review \& editing. Lucie Vandewalle: Supervision. Özlem Cizer: Supervision, Writing - review \& editing.

\section{Declaration of Competing Interest}

The authors declare that they have no known competing financial interests or personal relationships that could have appeared to influence the work reported in this paper.

\section{References}

[1] W. Chen, H.J.H. Brouwers, The hydration of slag. Part 1: Reaction models for alkali-activated slag, J. Mater. Sci. 42 (2007) 428-443.

[2] T. Bakharev, J.G. Sanjayan, Y. Cheng, Alkali activation of Australian slag cements, Cem. Concr. Res. 29 (1999) 113-120.

[3] D.M. Roy, W. Jiang, M.R. Silsbee, Chloride diffusion in ordinary, blended, and alkali-activated cement pastes and its relation to other properties, Cem. Concr. Res. 30 (2000) 1879-1884.

[4] A.M. Rashad, A comprehensive overview about the influence of different additives on the properties of alkali-activated slag-A guide for Civil Engineer, Constr. Build. Mater. 47 (2013) 29-55.

[5] J.G. Jang, N.K. Lee, H.K. Lee, Fresh and hardened properties of alkali-activated fly ash/slag pastes with superplasticizers, Constr. Build. Mater. 50 (2014) 169176.

[6] G. Fang, W.K. Ho, W. Tu, M. Zhang, Workability and mechanical properties of alkali-activated fly ash-slag concrete cured at ambient temperature, Constr. Build. Mater. 172 (2018) 476-487.

[7] M. Palacios, P.F.G. Banfill, F. Puertas, Rheology and setting of alkali-activated slag pastes and mortars: effect of organic admixture, ACI Mater. J. 105 (2016) $140-148$.

[8] H. Ye, A. Radlińska, Shrinkage mechanisms of alkali-activated slag, Cem. Concr. Res. 88 (2016) 126-135.

[9] C. Cartwright, F. Rajabipour, A. Radlińska, Shrinkage characteristics of alkaliactivated slag cements, J. Mater. Civil Eng. 27 (7) (2015).

[10] F. Pacheco-Torgal, J.A. Labrincha, C. Leonelli, A. Palomo, P. Chindaprasirt, Handbook of Alkali-activated Cements, Mortars and Concretes, Elsevier Ltd, 2015.

[11] W. Wang, H. Wang, M. Lo, The fresh and engineering properties of alkali activated slag as a function of fly ash replacement and alkali concentration, Constr. Build. Mater. 224-229 (2015) 84.

[12] J.I. Escalante-Garcí, A.F. Fuentes, A. Gorokhovsky, P.E. Fraire-Luna, G. MendozaSuarez, Hydration products and reactivity of blast-furnace slag activated by various alkalis, J. Am. Ceram. Soc. 86 (2004) 2148-2153.

[13] J.L. Provis, Geopolymers and other alkali activated materials: why, how, and what?, Mater Struct. 47 (2014) 11-25.

[14] J.I. Escalante-Garcia, K. Campos-Venegas, A.V. Gorokhovsky, A. Fernández, Cementitious composites of pulverised fuel ash and blast furnace slag activated by sodium silicate: effect of $\mathrm{Na} 2 \mathrm{O}$ concentration and modulus, Adv. Appl. Ceram. 105 (2006) 201-208.
[15] A. Palomo, A. Fernández-Jiménez, G. Kovalchuk, L.M. Ordoñez, M.C. Naranjo, OPC-fly ash cementitious system: study of the gel binders produced during alkaline hydration, J. Mater. Sci. 42 (2007) 2958-2966.

[16] C.K. Yip, G.C. Lukey, J.S.J. van Deventer, The coexistence of geopolymeric and calcium silicate hydrate at the early stage of alkaline activation, Cem. Concr. Res. 35 (2005) 1688-1697.

[17] I. García-Lodeiro, A. Fernández-Jiménez, A. Palomo, D.E. Macphee, Effect of calcium additions on N-A-S-H cementitious gels, J. Am. Ceram. Soc. 93 (2010) 1934-1940.

[18] I. Garcia-Lodeiro, A. Palomo, A. Fernández-Jiménez, D.E. Macphee, Compatibility studies between N-A-S-H and C-A-S-H gels: study in the ternary diagram Na2O-CaO- Al2O3-SiO2-H2O, Cem. Concr. Res. 41 (2011) 923-931.

[19] S. Puligilla, P. Mondal, Role of slag in microstructural development and hardening of fly ash-slag geopolymer, Cem. Concr. Res. 43 (2013) 70-80.

[20] M. Nedeljković, Z. Li, G. Ye, Setting, strength, and autogenous shrinkage of alkali-activated fly ash and slag pastes: effect of slag content, Materials (2018).

[21] M. Chi, Y. Chun Liu, Effects of fly ash/slag ratio and liquid/binder ratio on strength of alkali-activated fly ash/slag mortars, Appl. Mech. Mater. 337 (2013) 50-54.

[22] A.M. Humad, A. Kothari, J.L. Provis, A. Cwirzen, The effect of blast furnace slag fly ash ratio on setting, strength, and shrinkage of alkali-activated pastes and concretes, Front. Mater 6 (2019).

[23] N.K. Lee, H.K. Lee, Setting and mechanical properties of alkali-activated fly ash/ slag concrete manufactured at room temperature, Constr. Build. Mater. 47 (2013) 1201-1209.

[24] P. Nath, P. Kumar Sarker, Effect of GGBFS on setting, workability and early strength properties of fly ash geopolymer concrete cured in ambient condition, Constr. Build. Mater. 66 (2014) 163-171.

[25] A. Fernández-Jiménez, F. Puertas, Setting of alkali-activated slag cement. Influence of activator nature, Adv. Cem. Res. 13 (2001) 115-121.

[26] H. Jansson, L. Tang, Parameters influencing the initial setting time of alkaliactivated ground granulated blast furnace slag materials, Norsk Betongforening 52 (2015).

[27] P. Chindaprasirt, P.D. Silva, K. Sagoe-Crentsil, S. Hanjitsuwan, Effect of SiO2 and Al2O3 on the setting and hardening of high calcium fly ash-based geopolymer systems Hydration of alkali-activated slag: comparison with ordinary Portland cement, J. Mater. Sci. 47 (2012) 4876-4883.

[28] J.J. Chang, A study on the setting characteristics of sodium silicate-activated slag pastes, Cem. Concr. Res. 33 (7) (2003) 1005-1011.

[29] N. Marjanović, M. Komljenović, Z. Baščarević, V. Nikolić, R. Petrović, Physicalmechanical and microstructural properties of alkali-activated fly ash-blast furnace slag blends, Ceram. Int. 41 (1) (2015) 1421-1435.

[30] X. Gao, Alkali activated slag-fly ash binders: design PhD Thesis, TU Eindhoven, Netherland, 2018.

[31] V. Živica, Effects of type and dosage of alkaline activator and temperature on the properties of alkali-activated slag mixtures, Const. Build. Mater 21 (7) (2007) 1463-1469.

[32] S. Aydın, B. Baradan, Effect of activator type and content on properties of alkali-activated slag mortars, Compos. B Eng. 57 (2014) 166-172.

[33] J.L. Provis, J.S.J. van Deventer, Alkali-activated materials: State-of-the-art RILEM TC 224-AAM, Springer, Dordrecht Heidelberg New York London, London, 2014.

[34] R. Cao, S. Zhang, N. Banthia, Y. Zhang, et al., Interpreting the early-age reaction process of alkali-activated slag by using combined embedded ultrasonic measurement, thermal analysis, XRD, FTIR and SEM, Compos. Part B: Eng. 186 (2020) 107840.

[35] A.R. Brough, A. Atkinson, Sodium silicate-based, alkali-activated slag mortars: Part I. Strength, hydration and microstructure, Cem. Concr. Res. 32 (6) (2002) 865-879.

[36] B.C. McLellan, R.P. Williams, J. Lay, A. Riessen, G.D. Corder, Costs and carbon emissions for geopolymer pastes in comparison to ordinary portland cement, J. Clean. Prod 19 (2011) 9-10.

[37] A.M. Rashad, Y. Bai, P.A.M. Basheer, N.B. Milestone, N.C. Collier, Hydration and properties of sodium sulfate activated slag, Cem. Concr. Compos. 37 (2013) 20-29.

[38] A.F. Abdalqader, Fei Jin, AbirAl-Tabbaa, Development of greener alkaliactivated cement: utilisation of sodium carbonate for activating slag and fly ash mixtures, J. Cleaner Prod. 113 (2016) 66-75.

[39] S.A. Bernal, R.S. Nicolas, J.S.J. van Deventer, J.L. Provis, Alkali-activated slag cements produced with a blended sodium carbonate/sodium silicate activator, Adv. Cement Res. 28 (4) (2016) 262-273.

[40] B. Yuan, Q.L. Yu, H.J.H. Brouwers, Phase modification induced drying shrinkage reduction on $\mathrm{Na} 2 \mathrm{CO} 3$ activated slag by incorporating Na2SO4, Mater. Struct. 50 (5) (2017) 220. 
[41] S. Uppalapati, O. Cizer, Early-age properties of alkali-activated slag/fly ash blends, in: 2nd International RILEM/COST Conference on Early Age Cracking and Serviceability in Cement-based Materials and Structures - EAC2, Brussels, Belgium, 2017.

[42] A. Boumiz, C. Vernet, F.C. Tenoudji, Mechanical properties of cement pastes and mortars at early ages: evolution with time and degree of hydration, Adv. Cem. Based Mater. 3 (3-4) (1996) 94-106.

[43] J. Keating, D.J. Hannant, A.P. Hibbert, Comparison of shear modulus and pulse velocity techniques to measure the build-up of structure in fresh cement pastes used in oil well cementing, Cem. Concr. Res. 19 (4) (1989) 554-566.

[44] R. D'Angelo, T.J. Plona, L.M. Schwartz, P. Coveney, Ultrasonic measurements on hydrating cement slurries: onset of shear wave propagation, Adv. Cem. Based Mater. 2 (1) (1995) 8-14.

[45] B. Desmet, K.C. Atitung, et al., Monitoring the early-age hydration of selfcompacting concrete using ultrasonic p-wave transmission and isothermal calorimetry, Mater. Struct. 44 (2011) 1537-1558.

[46] J. Carette, S. Staquet, Monitoring the setting process of eco-binders by ultrasonic P-waveand S-wave transmission velocity measurement: mortar vs concrete, Constr. Build. Mater. 110 (2016) 32-41.

[47] X. Chen, A. Sutrisno, L.J. Struble, Effects of calcium on setting mechanism of metakaolin-based geopolymer, J. Am. Ceram. Soc. 101 (2) (2018) 957-968.

[48] X. Chen, A. Sutrisno, L. Zhu, L.J. Struble, Setting and nanostructural evolution of metakaolin geopolymer, J. Am. Ceram. Soc. 100 (5) (2017) 2285-2295.

[49] P. Suraneni, S. Puligilla, Eric H. Kim, et al., Monitoring setting of geopolymers, Adv. Civil Eng. Mater. 177 (3) (2014).

[50] A. Buchwald, R. Tatarin, D. Stephan, Reaction progress of alkaline-activated metakaolin-ground granulated blast furnace slag blends, J. Mater. Sci. 40 (20) (2009) 5609-5617.

[51] J. Lawson, B. Varela, R.S.P. Panandiker, M. Helguera, Determining the elastic prop- erties of geopolymers using non-destructive ultrasonic techniques, Dev. Strateg. Mater. Ceram. Eng. Sci 29 (10) (2008) 143-153.

[52] EUROPEAN COMMITEE FOR STANDARDIZATION, EN 196-3 Methods of testing cement - Part 3: Determination of setting times and soundness, 2016

[53] EUROPEAN COMMITTEE FOR STANDARIZATION, EN 12504-4 Testing concrete - Part 4: Deteremintion of ultrasonic pulse velcoity, 2004.

[54] H. von Daake, D. Stephan, Setting of cement with controlled superplasticizer addition monitored by ultrasonic measurements and calorimetry, Cem. Concr. Compos. 66 (2016) 24-37.

[55] Siva Uppalapati, Luice Vandewalle, Özlem Cizer, Autogenous shrinkage of slagfly ash blends activated with hybrid sodium silicate and sodium sulfate at different curing temperature, Construction and Building Materials 265 (2020) 121276, https://doi.org/10.1016/j.conbuildmat.2020.121276.

[56] S. Uppalapati, O. Cizer, Understanding the autogenous shrinkage in alkaliactivated slag/fly-ash blends, in: Int. Conf. ALKALI Act. Mater. GEOPOLYMERS VERSATILE Mater. Offer. HIGH Perform. LOW Emiss, 2018.

[57] X. Ke, S.A. Bernal, J.L. Provis, Controlling the reaction kinetics of sodium carbonate-activated slag cements using calcined layered double hydroxides, Cem. Concr. Res. 81 (2016) 24-37.

[58] S. Song, H.M. Jennings, Pore solution chemistry of alkali-activated ground granulated blast-furnace slag, Cem. Concr. Res. 29 (2) (1999) 15-170.

[59] W. Chen, Y. Li, P. Shen, Z. Shui, Microstructural development of hydrating Portland cement paste at early ages investigated with non-destructive methods and numerical simulation, J. Nondestr. Eval. 32 (2013) 228-237.

[60] G. Trtnik, M. Ivan Valič, F. Kavčič, G. Turk, Comparison between two ultrasonic methods in their ability to monitor the setting process of cement pastes, Cem. Concr. Res. 39 (10) (2009) 876-882.

[61] L. Wang, H.Q. Yang, S.H. Zhou, E. Chen, S.W. Tang, Mechanical properties, longterm hydration heat, shinkage behavior and crack resistance of dam concrete designed with low heat Portland (LHP) cement and fly ash, Constr. Build. Mater. 187 (2018) 1073-1091.

[62] G. Ye, Experimental Study and Numerical Simulation of the Development of the Microstructure and Permeability of Cementitious Materials PhD Thesis, TU Delft, Netherlands, 2003.

[63] N. Robeyst, Monitoring setting and microstructure development in fresh concrete with the ultrasonic through-transmission method PhD thesis, Ghent University, Belgium, 2010.

[64] S.W. Dean, Richard M. Kmack, K.E. Kurtis, et al., Assessment of air entrainment in fresh cement paste using ultrasonic nondestructive testing, J. ASTM Int. 71 (2010) 1-18.

[65] J. Zhu, S. Kee, Dongyeop Han, Yi-Te Tsai, Effects of air voids on ultrasonic wave propagation in early age cement pastes, Cem. Concr. Res. 1 (8) (2011) 872-881.

[66] G. Trtnik, G. Turk, F. Kavčič, V. Bokan Bosiljkov, Possibilities of using the ultrasonic wave transmission method to estimate initial setting time of cement paste, Cem. Concr. Res. 38 (11) (2008) 1336-1342.
[67] D. Krizan, B. Zivanovic, Effects of dosage and modulus of water glass on early hydration of alkali-slag cements, Cem. Concr. Res. 32 (8) (2002) 1181-1188.

[68] O. Burciaga-Diaz, J.I. Escalante-Gracia, Structure, mechanisms of reaction, and strength of an alkali-activated blast-furnace slag, J. Am. Ceram. Soc. 96 (12) (2013) 3939-3948.

[69] L. Weng, K. Sagoe-Crentsil, Dissolution processes, hydrolysis and condensation reactions during geopolymer synthesis: Part I-Low Si/Al ratio systems, J. Mater. Sci. 96 (12) (2007) 2997-3006.

[70] A. Palomo, M.W. Grutzeck, M.T. Blanco, Alkali-activated fly ashes: a cement for the future, Cem. Concr. Res. 29 (8) (1999) 1323-1329.

[71] P. Duxson, A. Fernández-Jiménez, J.L. Provis, G.C. Lukey, A. Palomo, J.S.J. van Deventer, Geopolymer technology: the current state of the art, J. Mater. Sci. 42 (9) (2007) 2917-2933.

[72] D. Hou, H. Ma, Z. Li, Morphology of calcium silicate hydrate (C-S-H) gel: a molecular dynamic study, Adv. Cem. Res. 27 (3) (2015) 135-146.

[73] A. Gruskovnjak, B. Lothenbach, L. Holzer, R. Figi, F. Winnefeld, Hydration of alkali-activated slag: comparison with ordinary Portland cement, Adv. Cem. Res. 18 (3) (2006) 119-128.

[74] S. Wang, K.L. Scrivener, Hydration products of alkali activated slag cement, Cem. Concr. Res. 25 (3) (1995) 561-571.

[75] M. Yuwei, Microstructure and Engineering Properties of Alkali Activated Fly Ash -as an environment friendly alternative to Portland cement PhD thesis, TU Delft, Netherland, 2013.

[76] B.S. Gebregziabiher, R. Thomas, S. Peethamparan, Very early-age reaction kinetics and microstructural development in alkali-activated slag, Cem. Concr. Compos. 55 (2015) 91-102.

[77] C. Shi, R.L. Day, A calorimetric study of early hydration of alkali-slag cements, Cem. Concr. Res. 25 (6) (1995) 1333-1346.

[78] S.A. Bernal, J.L. Provis, V. Rose, R. Mejía de Gutierrez, Evolution of binder structure in sodium silicate-activated slag-metakaolin blends, Cem. Concr. Compos. 33 (1) (2011) 46-54.

[79] S.A. Bernal, J.L. Provis, R.J. Myers, R.S. Nicolas, J.S.J. van Deventer, Role of carbonates in the chemical evolution of sodium carbonate-activated slag binders, Mater. Struct. 48 (3) (2014) 1-13.

[80] N. Mobasher, S.A. Bernal, J.L. Provis, Structural evolution of an alkali sulfate activated slag cement, J. Nucl. Mater. 97-104 (2016) 97-104.

[81] C. Paglia, F. Wombacher, H. Böhni, The influence of alkali-free and alkaline shotcrete accelerators within cement systems: I. Characterization of the setting behavior, Cem. Concr. Res. 31 (6) (2001) 913-918.

[82] C.J. Hampson, J.E. Bailey, On the structure of some precipitated calcium aluminsulphate hydrates, J. Mater. Sci. 71 (1982) 3341-3346.

[83] H.A. Razak, F. Sajedi, The effect of heat treatment on the compressive strength of cement-slag mortars, Mater. Des. 32 (8-9) (2011) 4618-4628.

[84] D. Torréns-Martín, L. Fernández-Carrasco, Effect of sulfate content on cement mixtures, Constr. Build. Mater. 48 (2013) 144-150.

[85] S. Wistuba, D. Stephan, G. Raudaschl-Sieber, J. Plank, Hydration and hydration products of two-phase Portland cement clinker doped with Na2O, Adv. Cem. Res. 19 (3) (2007) 125-131.

[86] S. Uppalapati, Ö. Cizer, Assessing the Autogenous Shrinkage of Alkali-Activated Slag/Fly Ash Mortar Blends, ACI special publication, pp. 23.1-23.12, 2017.

[87] C.U. Grosse, Ultrasound through-transmission techniques for quality control of fresh concrete, in: Conference on advanced testing of fresh cementinious materials, 2008.

[88] C. Van Bunderen, Experimental analysis and numerical modelling of concrete recycling flash calcined dredging sediments $\mathrm{PhD}$ thesis, KU Leuven, Leuven, Belgium, 2020.

[89] N. Robeyst, E. Gruyaert, C.U. Grosse, N. De Belie, Monitoring the setting of concrete containing blast-furnace slag by measuring the ultrasonic p-wave velocity, Cem. Concr. Res. 38 (10) (2008) 1169-1176.

[90] T. Kamada, S. Uchida, K. Rokugo, Nondestructive evaluation of setting and hardening of cement paste based on ultrasonic propagation characteristics, J. Adv. Concr. Technol. 3 (3) (2005) 343-353.

[91] P. Mounanga, V. Baroghel-Bouny, A. Loukili, A. Khelidj, Autogenous deformations of cement pastes: Part I. Temperature effects at early age and micro-macro correlations, Cem. Concr. Res. 36 (1) (2006) 110-112.

[92] J. Carette, Towards Early Age Characterisation of Eco-Concrete Containing BlastFurnace Slag and Limestone Filler PhD thesis, ULB, Brussels, Belgium, 2015.

[93] A. Fernandez-Jimenez, F. Puertas, A. Arteaga, Determination of kinetic equations of alkaline activation of blast furnace slag by means of calorimetric data, J. Therm. Anal. Calorim. 52 (3) (1998) 945-955.

[94] I. Pane, W. Hansen, Concrete hydration and mechanical properties under nonisothermal conditions, ACI Mater. J. 99 (6) (2002) 534-542.

[95] A.K. Schindler, K.J. Folliard, Heat of hydration models for cementitious materials, ACI Mater. J. 102 (2005) 24-33. 